\title{
PESQUISAS SOBRE FORMAÇÃO DE PROFESSORES NO MATO GROSSO DO SUL: O QUE SINALIZA A PRODUÇÃO DOS PROGRAMAS DE PÓS-GRADUAÇÃO EM EDUCAÇÃO?
}

Investigación sobre la formación de profesores en Mato Grosso do Sul: lo que señala la producción de programas de posgrado en educación

Research on teacher training in Mato Grosso do Sul: what signals the production of graduate programs in education

Andréia Nunes Militão*

https://doi.org/10.38117/2675-181X.formov2020.v2i2n4.477-496

\section{RESUMO}

O trabalho em tela elege como objeto a formação de professores e como universo da pesquisa aqui empreendida os programas de pós-graduação em educação situados no estado de Mato Grosso do Sul (MS). Almeja-se, portanto, verificar o que tem sido produzido no campo da formação de professores nessa localidade. Para a busca dos trabalhos, foram definidos três descritores: formação de professores, formação inicial e formação continuada e termos assemelhados a estes unitermos. O trabalho se caracteriza como uma meta pesquisa com uso de pesquisa documental e mapeamento da produção. O mapeamento considerou os dados disponibilizados nos repositórios dos seis programas investigados, na página eletrônica da universidade a que está vinculado e, por fim, os dados disponibilizados no Banco de Teses e Dissertações da CAPES e na Biblioteca Digital Brasileira de Teses e Dissertações (BDTD). Para a identificação e análise da produção considerou-se: títulos, resumos, palavras-chaves, instituições, ano de defesa e orientador e temática central. O mapeamento empreendido permite localizar no MS um processo de crescimento dos estudos sobre formação de professores interligado com a recente expansão do número de programas de pósgraduação em educação. No espectro de 74 trabalhos, identificou-se como características: a variedade temática, o tratamento da formação de professores de forma transversal, configurando uma espécie de formação focalizada, pois a centralidade está na formação docente para atuar em determinados contextos.

PALAVRAS-CHAVE: Mapeamento de Produção; Formação de Professores; Formação Inicial; Formação Continuada. 


\section{RESUMEN}

El trabajo sobre lienzo elige la formación de docentes como un objeto y los programas de educación de posgrado en el estado de Mato Grosso do Sul (MS) como el universo de investigación realizado aquí. Por lo tanto, tiene como objetivo verificar lo que se ha producido en el campo de la formación del profesorado en ese lugar. Para la búsqueda de producciones, se definieron tres descriptores: formación del profesorado, formación inicial y formación continua y palabras similares a estos términos. El trabajo se caracteriza por una meta investigación que utiliza investigación documental y mapeo de producción. El mapeo consideró los datos disponibles en los repositorios de los seis programas investigados, en el sitio web de la universidad a la que está vinculado y, finalmente, los datos disponibles en el Banco de Tesis y Disertaciones de CAPES y en la Biblioteca Digital de Tesis y Disertaciones de Brasil (BDTD). Para la identificación y análisis de la producción se consideró: títulos, resúmenes, palabras clave, instituciones, año de defensa y asesor y tema central. El mapeo realizado permite ubicar en el MS un proceso de crecimiento en los estudios sobre capacitación docente vinculado a la reciente expansión en el número de programas de posgrado en educación. En el espectro de 74 obras, se identificaron las siguientes características: la variedad temática, el tratamiento de la formación del profesorado de forma transversal, configurando un tipo de formación focalizada, ya que lo fundamental es la formación del profesorado para trabajar en determinados contextos.

PALABRAS CLAVE: Mapeo de producción; Formación de profesores; Formación inicial; Educación Continua.

\section{ABSTRACT}

The work has teacher education as an object, and Education graduate programs in the state of Mato Grosso do Sul (MS) as the research universe. It aims to verify what has been produced in the field of teacher education in that location. For the search, we defined three descriptors: teacher education, initial formation, and continuing teacher education. The work is characterized as a meta-research using documentary research and mapping production. The mapping considered the available repositories data of the six investigated programs, at the hold University website, and, finally, the available data at CAPES Theses and Dissertations Bank and the Brazilian Digital Library of Theses and Dissertations (BDTD). For identification and analysis of the production it was considered: titles, abstracts, keywords, institutions, year of defense and advisor and central theme. Mapping makes possible to locate in the MS a process of growth in studies on teacher education linked to the recent expansion in the number of graduate programs in education. In the spectrum of 74 works, the following characteristics were identified: the thematic variety, the treatment of teacher education in a transversal way, configuring a kind of focused formation, since centrality is in teacher education to work in certain contexts.

KEYWORDS: Production Mapping; Teacher education; Initial formation; Continuing Education. 
PESQUISAS SOBRE FORMAÇÃO DE PROFESSORES NO MATO GROSSO DO SUL:

O que sinaliza a produção dos programas de pós-graduação em educação?

\section{Introdução}

A acepção de formação de professores que baliza o presente trabalho considera que a formação inicial e a formação continuada estão amalgamadas num "[...] processo de desenvolvimento contínuo do professor, acentuando-se a unidade desse processo na diversidade de suas fases: formação pré-serviço ou inicial e formação em serviço ou continuada" (BRZEZINSKI; GARRIDO, 2001, p. 83).

Diniz-Pereira (2013) indica a emergência, em âmbito mundial, da formação de professores enquanto campo de pesquisa no limiar da década de 1970, situando sua materialização na década de 1980. Destaca "No Brasil, observam-se mudanças de ênfase em relação às pesquisas sobre formação docente, influenciadas por transformações conjunturais e pelo contato com a produção acadêmica da área realizada fora do país" (DINIZ-PEREIRA, 2013, p. 152). Romanowski (2013), localiza o trabalho de Gouveia como precursor dos estudos do tipo:

Um dos primeiros balanços sobre a pesquisa em educação no Brasil, realizado por Gouveia em 1971, ao examinar os estudos desenvolvidos por Centros de Pesquisas Regionais, vinculados ao INEP/MEC, aponta a realização de levantamento sobre a caracterização de professores e profissionais de ensino, quanto ao nível de qualificação, condições socioeconômicas, posição funcional e expectativas dos professores. Esses estudos são diagnósticos sobre a condição de formação. (ROMANOWSKI, 2013, p. 480)

É possível localizar, nas últimas décadas, um exponencial crescimento da produção acadêmica em todas as áreas do conhecimento, decorrentes diretamente da expansão da pós-graduação. Em âmbito nacional, a emergência da pós-graduação ocorre nas décadas de 1960 e 1970 induzida, notadamente pela Reforma Universitária de 1968 que, dentre outras medidas, estabeleceu como padrão a contratação de docentes pelo regime de tempo integral/dedicação exclusiva integrando, assim, a pós-graduação à carreira docente.

As décadas de 1980 e 1990, período marcado por forte crise econômica e por reformas do Estado de viés neoliberal incidiu na lenta expansão da pós-graduação no Brasil. No limiar do século XXI assistimos uma aceleração no processo de criação de novos cursos e aumento de matrículas.

No Mato Grosso do Sul observa-se forte concentração das matrículas da pósgraduação nas universidades federais com mais de 50\% do total. Magalhães (2019) ressalta que o processo de expansão, nesse estado, se deu de forma diferenciada, 
sobretudo, pelo caráter recente da criação de universidades federais nesta localidade Universidade Federal do Mato Grosso do Sul (UFMS) criada em 1979 e Universidade Federal da Grande Dourados (UFGD) em 2005. Soma-se, ainda, a criação da Universidade Estadual de Mato Grosso do Sul (UEMS) em 1993 cuja missão esteve focada no ensino de graduação. A criação de cursos de pós-graduação por esta universidade ocorreu em período mais recente, registrando em 2010 apenas três programas de mestrado. Até o início dos anos 2000, o estado de Mato Grosso do Sul contava com apenas uma universidade federal e reduzido número de docentes com titulação de doutor (menos de $25 \%$ nas universidades federais) e baixo número de cursos de pós-graduação totalizando 13 em 2002, destes, somente um da área de educação.

A partir de 2003, os programas de expansão dos cursos de graduação como o Expandir e o Programa de Apoio a Planos de Reestruturação e Expansão das Universidades Federais (REUNI) criaram condições para certa recuperação das universidades federais, principalmente com aumento de pessoal, atraindo para o estado recém doutores, aspecto que convergiu para o aumento da oferta não só da graduação como da pós-graduação. Para Magalhães (2019, p. 245), "Particularmente a atratividade de recém-doutores foi significativa no sentido de ampliar uma cultura voltada para o habitus da pós-graduação nessas instituições".

A relação entre esses programas voltados para ampliação de cursos de graduação e a expansão da pós-graduação em Mato Grosso do Sul, pode ser explicitada pela “[...] proporção de doutores com relação ao total de funções docentes dessas instituições saltou de menos de 30\% em 2003 para 62\% em 2017" (MAGALHÃES, 2019, p. 245). Portanto, a criação de programas de pós-graduação iniciada no estado no final da década de 1980 tem uma expansão em momento posterior ao observado no cenário nacional com uma média do crescimento de matrículas acima da média nacional no período de 2003 a 2019. Esse crescimento,

[...] se deu pela combinação de políticas governamentais indutoras da expansão da educação superior - em que proporcionou certa recuperação das universidades federais, especialmente em termos de corpo docente - de ações de indução por parte dos gestores universitários no contexto das instituições e da própria ação docente, particularmente pela manutenção do habitus da pós-graduação adquirido em sua formação. (MAGALHÃES, 2019, p. 250)

O crescimento da pós-graduação no estado reflete-se na rápida expansão dos programas de pós-graduação em educação, tendo em 2020 seis cursos de mestrado acadêmico, um de mestrado profissional e três de doutorado. Decorre dessa profusão de cursos, uma rápida expansão da produção acadêmica no Estado.

Esse texto tem como objetivo analisar a produção dos programas de pósgraduação em educação tendo como foco o campo da formação de professores, elegendo 
PESQUISAS SOBRE FORMAÇÃO DE PROFESSORES NO MATO GROSSO DO SUL:

O que sinaliza a produção dos programas de pós-graduação em educação?

como recorte espacial o estado de Mato Grosso do Sul. Caracteriza-se, portanto, como uma meta-pesquisa com uso de pesquisa documental para o mapeamento da produção.

A presente análise está organizada em quatro seções, iniciando com esta introdução. Na sequência, a seção denominada "Estado da Arte, Estado do Conhecimento: um debate necessário", discute os conceitos e procedimentos atinentes a esse tipo de pesquisa no sentido de embasar a investigação realizada. Na terceira parte do trabalho, intitulada "Mapeamento da produção sobre formação de professores nos Programas de Pós-graduação em Educação" apresenta uma sistematização e análise dos dados sobre a produção identificada, seguida do item "Apontamentos finais" onde procura-se tecer algumas considerações sobre os resultados da pesquisa realizada.

\section{Estado da Arte, Estado do Conhecimento: um debate necessário}

A constituição da formação de professores enquanto campo de conhecimento gerou a produção de estados da arte ainda na década de 1980. Neste sentido, Diniz-Pereira (2013, p. 146) localiza os estudos efetuados e publicados por: "Feldens (1983, 1984): de 1972 a 1981; Vera Candau (1987): de 1982 a 1985; Menga Lüdke (1994): de 1988 a 1994; Marli André (2006): de 1990 a 1998; Iria Brzezinski (2006): de 1997 a 2002". Romanowski (2013) adiciona "Nesse período, os debates em torno da pesquisa em formação de professores passaram a ocorrer em simpósios, reuniões, artigos, investigações, teses e dissertações".

A presença de pesquisa bibliográfica nos trabalhos acadêmicos é comum aos diversos campos do conhecimento. Diferentes nomenclaturas veem denominando essa etapa da pesquisa. Entre as designações mais comuns estão: revisão da literatura, levantamento bibliográfico, balanço, estado da arte, estado do conhecimento, levantamento da produção, mapeamento da produção, dentre outros termos similares.

Até a década de 1990, essa fase da pesquisa balizava-se essencialmente pela consulta direta às bibliotecas universitárias, processo explicado especialmente por não termos à disposição repositórios digitais e mesmo acesso às redes de internet para a maior parte dos pesquisadores brasileiros.

No tempo presente, denota-se a presença cada vez maior nas dissertações e teses de mapeamentos de produção. Talvez essa mudança se explique pela disponibilização de repositórios digitais que facilitam o acesso por meio da busca de descritores.

Sobre esse tipo de pesquisa, Romanowski e Ens (2006, p. 38), indicam os procedimentos e os possíveis limites dos estudos denominados de "Estado da arte". Para as autoras, "A realização de estados da arte possibilita a efetivação de balanço da pesquisa de uma determinada área”. Por meio desse tipo de pesquisa, é possível localizar a 
presença de produção de campos específicos nos programas de pós-graduação e nos eventos.

A expansão dos programas de pós-graduação, acompanhada pela disseminação de revistas impressas e digitais propiciou a intensificação de publicações nas diversas áreas do conhecimento. Esse aspecto modificou o que anteriormente denominávamos de "revisão da literatura" por "levantamento da produção", este último contempla aspectos de ordem mais quantitativa, detendo-se em localizar a quantidade de trabalhos, o ano da produção, o programa onde está inscrito, as palavras-chaves entre outros elementos.

A realização destes balanços possibilita contribuir com a organização e análise na definição de um campo, uma área, além de indicar possíveis contribuições da pesquisa para com as rupturas sociais. A análise do campo investigativo é fundamental neste tempo de intensas mudanças associadas aos avanços crescentes da ciência e da tecnologia. (ROMANOWSKI; ENS, 2006, p. 39)

Destarte esses procedimentos permitam indiciar aspectos gerais de um determinado campo do conhecimento, concordamos com Romanowski e Ens (2006, p. 39):

\begin{abstract}
Estados da arte podem significar uma contribuição importante na constituição do campo teórico de uma área de conhecimento, pois procuram identificar os aportes significativos da construção da teoria e prática pedagógica, apontar as restrições sobre o campo em que se move a pesquisa, as suas lacunas de disseminação, identificar experiências inovadoras investigadas que apontem alternativas de solução para os problemas da prática e reconhecer as contribuições da pesquisa na constituição de propostas na área focalizada.
\end{abstract}

Destacam as autoras que esses trabalhos se caracterizam por um aprofundamento das análises realizadas, tanto no aspecto de sua abrangência, quanto nos elementos objeto de reflexões:

Essas análises possibilitam examinar as ênfases e temas abordados nas pesquisas; os referenciais teóricos que subsidiaram as investigações; a relação entre o pesquisador e a prática pedagógica; as sugestões e proposições apresentadas pelos pesquisadores; as contribuições da pesquisa para mudança e inovações da prática pedagógica; a contribuição dos professores/pesquisadores na definição das tendências do campo de formação de professores. (ROMANOWSKI; ENS, 2006, p. 39)

Enquanto os procedimentos denominados de balanço, levantamento e mapeamento restringem-se aos aspectos de localização e quantificação, os estudos caracterizados de estado da arte "[...] não se restringem a identificar a produção, mas analisá-la, categorizá-la e revelar os múltiplos enfoques e perspectivas” 
PESQUISAS SOBRE FORMAÇÃO DE PROFESSORES NO MATO GROSSO DO SUL:

O que sinaliza a produção dos programas de pós-graduação em educação?

(ROMANOWSKI; ENS, 2006, p. 39). As autoras estabelecem a distinção entre estado da arte e estado do conhecimento. Consideram que "os estudos de 'estado da arte' que objetivam a sistematização da produção numa determinada área do conhecimento já se tornaram imprescindíveis para apreender a amplitude do que vem sendo produzido". Portanto, têm maior abrangência, envolvem a localização e análise de artigos, anais de eventos, dissertações e teses da área. Enquanto que "O estudo que aborda apenas um setor das publicações sobre o tema estudado vem sendo denominado de "estado do conhecimento" (ROMANOWSKI; ENS, 2006, p.39-40).

Para Ferreira (2002, p. 258), há uma aproximação das pesquisas do tipo "estado da arte" e "estado do conhecimento" e estas similaridades se caracterizam por serem:

Definidas como de caráter bibliográfico, elas parecem trazer em comum o desafio de mapear e de discutir uma certa produção acadêmica em diferentes campos do conhecimento, tentando responder que aspectos e dimensões vêm sendo destacados e privilegiados em diferentes épocas e lugares, de que formas e em que condições têm sido produzidas certas dissertações de mestrado, teses de doutorado, publicações em periódicos e comunicações em anais de congressos e de seminários. Também são reconhecidas por realizarem uma metodologia de caráter inventariante e descritivo da produção acadêmica e científica sobre o tema que busca investigar, à luz de categorias e facetas que se caracterizam enquanto tais em cada trabalho e no conjunto deles, sob os quais o fenômeno passa a ser analisado.

Outra distinção possível indica que o "estado da arte" configuraria um tipo de pesquisa enquanto "estado do conhecimento" comporia todas as pesquisas, representando, uma etapa da investigação.

Angelucci e colaboradoras (2004) consideram:

A importância de balanços periódicos do estado de coisas vigente numa área de pesquisa é múltipla. Eles podem detectar teoria e método dominantes; pôr em relevo aspectos do objeto de estudo que se esboçam nas entrelinhas das novas pesquisas; revelar em que medida a pesquisa recente relaciona-se com a anterior e vai tecendo uma trama que permita avançar na compreensão do objeto de estudo pela via do real acréscimo ao que já se conhece ou da superação de concepções anteriores. Só assim se podem avaliar as continuidades e descontinuidades teóricas e metodológicas e o quanto esta história se faz por repetição ou ruptura - noutras palavras, o quanto ela redunda ou avança na produção de saber sobre o objeto de estudo. Nesse tecido, sempre em formação, reside a possibilidade de evitar a cristalização do conhecimento e de fazer da pesquisa espaço de produção de saber, que tem como essência o constante movimento.

Romanowski e Ens (2006, p. 41) acrescentam que "Esses estudos são justificados por possibilitarem uma visão geral do que vem sendo produzido na área e uma ordenação 
que permite aos interessados perceberem a evolução das pesquisas na área, bem como suas características e foco, além de identificar as lacunas ainda existentes".

Em estudo anterior Romanowski (2002, p.15-16) indicou os procedimentos/passos necessários para a realização de uma pesquisa do tipo estado da arte: definição dos descritores, dos repositórios para busca e de critérios para a seleção do material de análise, coleta do material de pesquisa, leitura e síntese dos trabalhos localizados, considerando os elementos tema, objetivos, problemáticas, metodologias, conclusões e a relação entre o pesquisador e a área, sistematização das sínteses e, por fim, a elaboração das conclusões.

Ferreira (2002) apoia-se em Soares (1987, p. 3) para enfatizar a importância da realização de estudos do tipo estado do conhecimento, especialmente porque contribuem para a organização do conhecimento produzido "[...] ordenação que permita indicação das possibilidades de integração de diferentes perspectivas, aparentemente autônomas, a identificação de duplicações ou contradições, e a determinação de lacunas e vieses". Assim,

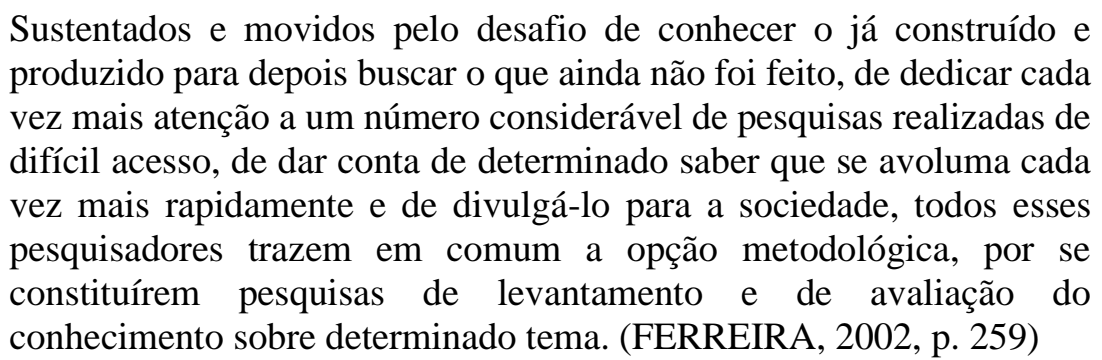

Anteriormente denominados de catálogos, os repositórios digitais permanecem com a mesma função apontada há quase duas décadas por Ferreira (2002, p. 261) “[...] permitem o rastreamento do já construído, orientam o leitor na pesquisa bibliográfica de produção de uma certa área".

Temos, ainda, a denominada revisão sistemática, que segundo Davies (2007, p. 32) "[...] ajudam a identificar o que se conhece sobre um tópico ou questão e, assim, direcionar novas pesquisas primárias nas áreas em que haja uma lacuna na base de evidências. Para Costa e Zoltowski (2014), a revisão sistemática envolve alguns procedimentos tais como a delimitação do tema, a seleção de fontes, a escolha de palavras-chave, a busca, a criação de um banco de dados, a triagem dos dados com explicitação de critérios de inclusão e de exclusão, seguidas da síntese e interpretação dos dados.

Na sequência, apresentamos alguns modelos de mapeamento de produção. Esses materiais foram localizados pelos títulos. Identifica-se grande quantidade de produções que têm esse caráter de meta pesquisa, buscando sistematizar a produção, destacamos 
alguns, mais recentes por indicarem um novo movimento metodológico, ora por elegerem um único repositório, ora por elegerem um determinado periódico ou ainda por recorrerem ao uso de software para a análise dos dados.

Um primeiro trabalho é o de Duarte (2010) que aborda a produção acadêmica sobre trabalho docente na educação básica no Brasil com recorte do período de 1987 a 2007. De natureza quantitativa, a autora elege dissertações e teses sobre o trabalho docente na educação básica. Para tanto, tem-se como fonte de pesquisa o Banco de Dissertações e Teses da Coordenação de Aperfeiçoamento de Pessoal de Nível Superior (CAPES) e realiza a busca por meio de sete descritores derivados da categoria principal 'trabalho docente' (DUARTE, 2010, p. 101). A autora informa que o trabalho integra um estado da arte e que essa parte do trabalho configura um processo de sistematização dos dados.

[...] inventariar o conjunto de trabalhos produzidos, ordená-los por períodos históricos, situar os principais aspectos investigados e os locais de produção, enfim, indicar alguns caminhos, escolhas e dimensões que esses estudos vêm tomando e que possam contribuir no fortalecimento desse campo de investigação. (DUARTE, 2010, p. 102)

Diferentemente do constatado por Duarte (2010) nos trabalhos produzidos entre os anos 1987 a 2007, que indicam "não haver, ou não ser cumprida, uma padronização para a sua apresentação", os trabalhos mais recentes indicam certa padronização dos resumos, pois passam a explicitar o programa, o grupo de pesquisa e/ou pesquisa guardachuva onde estão inscritos.

A opção por um único periódico para análise de um determinado campo do conhecimento tem sido trilhada por alguns pesquisadores. Nesta direção, temos o trabalho de Bueno e Souza (2018) que elegem a Revista Brasileira de Educação Especial demarcando para análise o período de 1992 a 2017. Os autores colocam como critério de seleção para escolha dos textos "três eixos de entrada: quem produziu esses artigos, o que produziram e por quais meios produziram essas narrativas" (BUENO; SOUZA, 2018, p. 33). Outro aspecto menos comum na área educacional é o uso de software para quantificação e análise de dados. Bueno e Souza (2018) recorrem ao Sphinx iQ2.

Adiciona-se às análises de um único periódico, o foco em um elemento de um campo de pesquisa. Para exemplificar, temos o artigo de Neres e Correa (2018) que analisa a área da deficiência visual a partir de publicações contidas na Revista Brasileira de Educação Especial entre 1992 e 2017. As autoras estabeleceram como critérios de recolha de material: "distribuição anual dos artigos, autoria, temas apresentados, regiões e instituições de origem, gêneros textuais e interfaces com outras áreas do conhecimento" (NERES; CORREA, 2018, p. 153). 
O estudo de Silva e Bego (2018) configura um levantamento bibliográfico. Os autores utilizam como critério de seleção os periódicos acadêmico-científicos de estratos A1 e A2 definidos pelo Qualis da CAPES.

Magalhães e Souza (2012, p. 669) destacam o aumento de estudos que envolvem levantamento de aspectos das produções no âmbito dos Programas de Pós-Graduação, consideram que "São relevantes os estudos avaliativos, sobretudo para os próprios Programas de Pós-Graduação, por permitirem a crítica do conhecimento produzido, apontando aspectos positivos e/ou negativos e por investirem na melhoria da produção".

\section{Mapeamento da produção sobre formação de professores nos Programas de Pós-graduação em Educação}

O mapeamento da produção sobre formação de professores dos programas de pósgraduação em educação, aqui empreendido, teve como fonte o repositório do Banco de Dissertações e Teses da Capes e a Biblioteca Digital Brasileira de Teses e Dissertações (BDTD). Para tanto, foram definidos três descritores: formação de professores, formação inicial e formação continuada e termos assemelhados a estes descritores, estabelecendo a combinação do descritor com a universidade e programa de pós-graduação de vinculação. Inicialmente, havíamos pensado partir dos repositórios dos próprios programas, no entanto, constatamos que estes não estavam atualizados.

À exemplo de Duarte (2010, p. 102), optamos por coletar "em cada dissertação e tese foram: título, autoria, orientador, tipo (mestrado ou doutorado), instituição, data de defesa, palavras-chave e resumo". O mapeamento da produção iniciou-se pela identificação dos programas de pós-graduação em educação existentes no estado de Mato Grosso do Sul, reconhecimento da estrutura e perfil de cada um dos programas de pósgraduação a partir das respectivas páginas eletrônicas onde buscamos dados referentes ao ano de criação, linhas de pesquisa, orientadores vinculados, dentre outros.

O estado de Mato Grosso do Sul dispõe de seis programas de pós-graduação em educação, sendo três cursos com oferta de mestrado e doutorado (UFMS/Campo Grande, UCDB e UFGD), todos com nota 5 na última avaliação da CAPES. Temos três cursos com oferta apenas do mestrado: UEMS/Paranaíba, UFMS/Corumbá e UFMS/Três Lagoas. Estes com nota 3 na avaliação da CAPES e um mestrado profissional (UEMS/Campo Grande), com nota 4 na última avaliação da CAPES.

Embora não se constitua como objeto deste texto, é importante ressaltar que existe um processo recente de expansão da pós-graduação no Brasil. O estudo de Magalhães (2019, p. 242), ao tratar da expansão da Pós-Graduação no estado de Mato Grosso do Sul 
PESQUISAS SOBRE FORMAÇÃO DE PROFESSORES NO MATO GROSSO DO SUL:

O que sinaliza a produção dos programas de pós-graduação em educação?

pondera que entre 2003 e 2016 a "proporção do incremento de matrículas e de programas de pós-graduação" permaneceu no Estado acima das médias nacionais.

Decorrente desse recente processo de expansão, denota-se que os cursos de pósgraduação da área de educação do estado possuem perfil muito diverso. A Universidade Federal do Mato Grosso do Sul (UFMS), campus de Campo Grande foi a primeira instituição do estado a ofertar o mestrado (1988) e depois o doutorado em 2006. Este programa conta, no repositório do banco digital de teses e dissertações (BDTD), com 319 registros de defesa de mestrado, desde 1999, data da defesa e 110 registros de defesa de tese desde 2008, data da primeira defesa. O site da instituição aponta para um número total de 357 mestres e 112 doutores formados. A Universidade Católica Dom Bosco (UCDB) criou em 1994 o curso mestrado em educação e, em 2010, o doutorado. Tratase da única instituição privada do estado a ofertar um programa de pós-graduação em educação. Em 2008, a Universidade Federal da Grande Dourados (UFGD) passou a ofertar o mestrado em educação e, em 2014, o doutorado, sendo a única instituição do estado a ofertar um doutorado fora da capital do estado.

A Universidade Estadual de Mato Grosso do Sul (UEMS) unidade de Paranaíba e a UFMS/Corumbá criaram no mesmo ano (2011) os programas acadêmicos de mestrado em educação. Em 2013, a UEMS/Campo Grande passou a ofertar o mestrado profissional e a UFMS/Três Lagoas criou o mestrado acadêmico em 2019, este último não conta com defesas até o presente momento.

A síntese apresentada no Quadro 01, permite identificar as linhas e respectivos programas que se dedicam ao estudo da formação de professores. Assim, com relação às linhas de pesquisa dos respectivos programas, temos:

\section{Quadro 01 - Linhas de pesquisa dos programas de pós-graduação do MS}

\begin{tabular}{|l|l|l|}
\hline Universidade & Programa & Linhas de Pesquisa \\
\hline $\begin{array}{l}\text { UFMS/Campo } \\
\text { Grande }\end{array}$ & M/D -Acadêmico & $\begin{array}{l}\text { 1. Educação, Cultura, Sociedade } \\
\text { 2. História, Políticas, Educação } \\
\text { 3.Processos Formativos, Práticas Educativas, } \\
\text { Diferenças }\end{array}$ \\
\hline UCDB/Campo & M/D -Acadêmico & $\begin{array}{l}\text { 1. Política, Gestão e História da Educação } \\
\text { 2.Práticas Pedagógicas e suas relações com a } \\
\text { Formação Docente } \\
\text { 3. Diversidade Cultural e Educação Indígena }\end{array}$ \\
\hline UFGD/Dourados & M/D -Acadêmico & $\begin{array}{l}\text { 1. História da Educação, Memória e Sociedade } \\
\text { 2. Políticas e Gestão da Educação } \\
\text { 3. Educação e Diversidade }\end{array}$ \\
\hline UEMS/Paranaíba & M - Acadêmico & $\begin{array}{l}\text { 1. Currículo, Formação Docente e Diversidade } \\
\text { 2. História, Sociedade e Educação }\end{array}$ \\
\hline
\end{tabular}




\begin{tabular}{|l|l|l|}
\hline & & 3. Linguagem, Educação e Cultura \\
\hline UFMS/Corumbá & M - Acadêmico & $\begin{array}{l}\text { 1.Políticas, Práticas Institucionais e } \\
\text { Exclusão/Inclusão Social } \\
\text { 2. Formação de Educadores e Diversidade } \\
\text { 3. Gênero e Sexualidades, Cultura, Educação e } \\
\text { Saúde }\end{array}$ \\
\hline $\begin{array}{l}\text { UEMS/Campo } \\
\text { Grande }\end{array}$ & M - Profissional \\
\hline UFMS/Três Lagoas & M - Acadêmico & $\begin{array}{l}\text { 1. Organização do Trabalho Didático } \\
\text { 2. Formação de Professores e Diversidade }\end{array}$ \\
\hline
\end{tabular}

Fonte: Elaborado pela autora a partir das páginas dos programas pesquisados, 2020 (grifos da autora).

A análise das nomenclaturas das linhas de pesquisa indica que, com exceção do programa de pós-graduação da UFGD, os demais programas contemplam a formação de professores. Expressos pelos unitermos na denominação das linhas: "processos formativos", "formação docente", "formação de educadores" e formação de professores".

A leitura das ementas das linhas de pesquisa indicou, ainda, que todos os programas contemplam o campo da formação de professores. No caso da UFGD que não explicita no nome das linhas o campo da formação de professores, foi possível localizar a presença em duas linhas de pesquisa: Linha Educação e Diversidade ao contemplar a "formação de profissionais da educação e na Linha História da Educação, Memória e Sociedade ao desenvolver pesquisas sobre as "relações entre história e memória na formação e na profissão docente".

Com relação a análise dos trabalhos - dissertações e teses - vinculadas aos programas denota-se que a formação de professores é transversal à todas as linhas dos programas, aspecto verificável pela produção e vinculação aos orientadores. Um exemplo de transversalidade da formação de professores pode ser facilmente constatado a partir da análise do PGEDU da UCDB que apesar de ter uma linha específica destinada ao campo da formação de professores denominada "Práticas Pedagógicas e suas relações com a Formação Docente" e abordar as temáticas: formação dos professores como mediadores do saber escolar, o professor e a sua formação (inicial e continuada), e as correlações possíveis entre as várias dimensões da prática pedagógica presente na escola e a formação de professores, as outras duas linhas vinculadas ao PGEDU/UCDB - "Política, Gestão e História da Educação" e "Diversidade Cultural e Educação Indígena" - também contemplam em suas ementas a possibilidade de desenvolvimento de pesquisas e orientação sobre formação, além de ofertarem disciplinas sobre a área, abordando respectivamente "políticas de formação inicial e continuada de professores" e "formação de professores para a educação intercultural". Essa mesma dinâmica na constituição das linhas de pesquisa dos programas foi observada nos demais programas analisados. 
PESQUISAS SOBRE FORMAÇÃO DE PROFESSORES NO MATO GROSSO DO SUL:

O que sinaliza a produção dos programas de pós-graduação em educação?

Embora seja uma constante a presença nas páginas eletrônicas da produção vinculada aos programas de pós-graduação, a consulta aos repositórios institucionais dos órgãos de fomento é mais comum, à exemplo do Banco de Teses e Dissertações da CAPES.

Considerando que para o mapeamento recorremos a dois repositórios - Banco de Teses e Dissertações da CAPES e Biblioteca Digital Brasileira de Teses e Dissertações (BDTD) - estabelecemos como critérios de exclusão a origem do trabalho ser de programa de área distinta da educação e a indisponibilidade de dados. Esse último critério afeta, especialmente, a UFMS/Campo Grande, pois as produções do início do programa não estão disponíveis, abrangendo o período de 1988 a 1999. Essa ausência pode ser explicada pela vinculação do PGEDU/UFMS/Campo Grande à Faculdade de Educação da Unicamp no início de seu funcionamento e também pela não obrigatoriedade de vinculação dos trabalhos a Plataforma Sucupira, as dissertações referentes à esse período disponibilizam apenas o ano de defesa, o título e autoria do trabalho, o que impossibilitou a análise comparativa com o restante da base de dados coletados.

A análise da produção dos programas pesquisados considerou como categorias analítica: a) distribuição das produções por instituição; b) tipo (mestrado/doutorado); c) ano de defesa; d) orientadores dos trabalhos; e) temática central do trabalho, identificada a partir dos títulos, resumos e palavras-chave.

A busca de trabalhos sobre formação de professores na UCDB retornou 24 trabalhos, abrangendo o período de 2013 a 2019, sendo seis (06) teses e 18 dissertações. Esses trabalhos se concentram sob a orientação de alguns docentes do curso, considerando apenas as duas com maior número de orientações no período, temos: Maria Cristina Lima Paniago com 07 produtos e Celeida Maria Costa de Souza 05 trabalhos sob sua orientação, têm-se 12 trabalhos, representando 50\% do total de trabalhos que versam sobre a formação de professores no período analisado. Cabe destacar que no período citado, temos nove (09) docentes com orientações concluídas no total. Com relação ao ano de defesa, temos: 2013 (03), 2014 (07), 2015 (04), 2016 (03), 2017 (03), 2018 (01) e 2019 (03).

Com relação ao foco dos trabalhos, constata-se uma profusão de temáticas que circundam a formação de professores. Em alguns casos, a formação docente não se configura como objeto central do trabalho, mas tratam de variadas questões que impactam a formação docente, ou ainda, como a formação docente prepara os professores para lidar com diferentes questões. Neste sentido, podemos citar: um trabalho que aborda os rebatimentos da Lei n. 10.630/2003 na formação docente para lidar com as questões étnico-raciais. Outro trabalho que investiga a formação de professores indígenas e professores não indígenas que atuam em escolas. Localizamos, ainda, trabalhos que 
tratam da formação docente a partir da análise de um programa específico, com destaque para o PIBID.

A formação de professores é também investigada sob o prisma disciplinar no currículo escolar da educação básica como as ciências (01), educação física (02), pedagogia (01), ou de outros cursos superiores como farmacêutica - bioquímica (01). Assim, temos nove trabalhos neste espectro que discutem a formação em contextos específicos, numa perspectiva de formação focalizada, baseada na análise de disciplinas específicas, de leis, programas e políticas, não tendo como foco central a discussão do campo de formação de professores em perspectiva mais ampla.

A formação continuada comparece também em seis (06) trabalhos sobre a preparação dos docentes para o uso de tecnologias em redes sociais (01), a inserção de tecnologias na formação inicial (01), o uso do computador em sala de aula (01), o trabalho com software específico como o SCRATCH (01). Destacam-se, ainda, trabalhos sobre formação continuada voltados para níveis/modalidades de educação, como: para a EJA (01), para a Educação Integral (01), para a educação infantil integral, totalizando seis trabalhos neste grupo.

Outros trabalhos problematizaram a contribuição das Olimpíadas de Língua Portuguesa para formação contínua, dois trabalhos que tratavam da formação de professores à distância e um sobre a formação de professores em nível médio.

Localizamos quatro produtos que tratam da formação inicial de forma mais direta, abrangendo a formação inicial para ensino técnico profissional, as artes cênicas, o curso de Letras Libras e sobre a educação do campo no curso de ciências sociais.

Denota-se, a partir, desses dados a multiplicidade temática contida nas teses e dissertações identificadas, não existindo um processo de acúmulo das discussões específicas do campo da formação de professores. Existe uma característica de foco em temáticas específicas, a partir das quais a formação de professores é analisada.

A busca da produção vinculada aos dois programas de pós-graduação em educação da UEMS não permitiu a separação dos dados destes programas, foi necessária a realização de busca nos próprios programas para essa identificação. Assim, temos três (03) produções no âmbito do mestrado acadêmico da UEMS/Paranaíba e seis (06) na UEMS/Campo Grande (profissional), totalizando nove (09) trabalhos, todos em nível de mestrado. Optamos pela análise conjunta dos dados, uma vez que se identifica similaridades nas produções, inclusive com mobilidade docente entre os programas, por pertencerem à mesma instituição. Aqui também há duas professoras com mais trabalhos no campo da formação de professores: Eliane Greice Davanco Nogueira com três (03) orientações concluídas e Bartolina Ramalho Catanante com duas (02), somando cinco 
PESQUISAS SOBRE FORMAÇÃO DE PROFESSORES NO MATO GROSSO DO SUL:

O que sinaliza a produção dos programas de pós-graduação em educação?

(05) trabalhos que representam mais da metade $(55,5 \%)$ do total, no total seis (06) professores foram identificados como orientadores de dissertações que produzem na área. Sobre o ano das defesas temos: 2013 (03), 2014 (02), 2015 (03), 2017 (01).

Em relação ao foco dos trabalhos, temos dois (02) sobre a formação continuada do alfabetizador a partir da análise dos programas Alfa e Beto e do PNAIC, um (01) enfoca a questão étnico-racial e de gênero, um (01) com foco na questão de gênero e um (01) na área de matemática. Localizamos, ainda, um (01) que versa sobre a formação inicial do professor de música, um (01) da pedagogia ofertada na modalidade à distância, um (01) da formação de professor para escola de tempo integral e, por fim, um (01) trabalho que analisa a Política de Formação Docente contida no Plano de Ações Articuladas (PAR).

A busca da produção referente a UFGD retornou um total de 16 trabalhos, sendo 02 teses e 14 dissertações. Observa-se maior dispersão de orientadores com um total de 11 docentes distribuídos na orientação dos 16 trabalhos, não evidenciando uma concentração como nos demais programas investigados. Destaca-se apenas a docente Elisângela Alves da Silva Scaff com 04 trabalhos, correspondendo a 25\% do total. Esse dado reflete a inexistência de uma linha específica, assim a temática perpassa pelas três linhas de forma indistinta.

Quanto aos temas dos trabalhos, estes não diferem muito das outras instituições, destaca-se apenas uma presença maior de trabalhos com foco no campo das políticas públicas de formação de professores. A formação continuada tem como foco a atuação/preparação de professores para trabalha com autismo, educação especial e escolas indígenas.

Os trabalhos que analisam programas e políticas específicas para a formação de professores conferiram ênfase ao Programa Escolas Interculturais de Fronteiras (PEIF), ao PAR, a formação continuada de professores alfabetizadores, de professores de Educação Física e de Pedagogia. No campo da história da educação, localizamos a necessidade de formação de professores leigos rurais.

Em relação à formação inicial de professores, as pesquisas identificadas tratam dos professores indígenas, professores de língua portuguesa, a relação entre a formação inicial e questões étnico-raciais e de inclusão. Em âmbito, alicerçado na política educacional, identificamos trabalhos que analisam a reformulação das licenciaturas, as políticas de formação de diretores e relação público privado na formação continuada de professores e as influências dos resultados da Prova Brasil sobre a formação continuada dos professores.

Um aspecto que chama a atenção a partir da análise das palavras-chave utilizadas é que trabalhos que tratam da formação inicial e continuada não indicam esses termos, 
que se concentram apenas no genérico e inespecífico "formação de professores", que apareceu em 14 dos 16 trabalhos, formação continuada apareceu somente em 03 e o termo política educacional em seis trabalhos, termos gerais como educação inclusiva, educação especial e autismo aparecem em 04 trabalhos. Com relação a proporção de trabalhos defendidos por ano, temos: 2010 (02), 2011 (01), 2012 (02), 2013 (01), 2014 (01), 2015 (01), 2018 (01) e 2019 (01).

Em relação ao mapeamento das produções da UFMS, assim como na UEMS, analisamos em conjunto a produção dos programas de Campo Grande, que possui mestrado e doutorado, e do programa de Corumbá que teve seu mestrado criado em 2011. O programa de Três Lagoas, criado em 2019, não compôs a análise, pois ainda não tem trabalhos defendidos.

O levantamento indica um total de 25 trabalhos identificados no período 2004 a 2016, sendo 4 teses e 21 dissertações. Em relação aos orientadores destacam-se Alda Maria do Nascimento Osório que tem seis orientações, entre os demais docentes nenhum tem mais que duas orientações no período. Nesta condição, temos Ângela Maria Zanon, Antônio Carlos do Nascimento Osório, Lucrécia Stringhetta Mello, Marilena Bittar, Shirley Takeco Gobara, ou seja, esses cinco docentes têm 10 orientações identificadas. Somando os trabalhos orientados por esses 6 docentes temos 16 teses e dissertações, ou $64 \%$ do total, outros nove docentes orientaram um trabalho cada um, neste período, somando um total de 15 orientadores identificados.

No que tange a temática, observa-se o mesmo perfil das demais universidades, com destaque para discussões sobre o uso de tecnologias e para a alfabetização. Localizamos três textos sobre a formação continuada para uso das tecnologias, dois sobre a formação do professor de matemática e cinco sobre a formação de professores alfabetizadores. Destes, três versam sobre o PROFA, um sobre o Pró-letramento e um sobre a formação de professores indígenas alfabetizadores.

Em relação à formação inicial, visualiza-se foco em áreas diversas, destacando-se um que trata dos conhecimentos de astronomia, dois sobre ciências com foco na questão ambiental, um na formação do professor de química, dois trabalhos com foco na educação infantil, e um que trata do recurso da educação à distância na formação inicial.

Identificamos ainda trabalhos contendo uma análise mais geral da formação do pedagogo, outro sobre a contribuição da sociologia educacional de Fernando de Azevedo, uma análise da história de uma escola normal e um trabalho sobre a formação do 'professor leitor'. Por fim, temos dois trabalhos que investigaram os impactos da formação continuada na prática docente em diferentes redes de ensino. 
PESQUISAS SOBRE FORMAÇÃO DE PROFESSORES NO MATO GROSSO DO SUL:

0 que sinaliza a produção dos programas de pós-graduação em educação?

Observa-se que em relação aos descritores/palavras-chave utilizadas nos trabalhos tem preponderância àquelas ligadas à formação continuada, associadas às áreas de matemática, ciências e tecnologias. Sobre a quantidade de defesas por ano, temos 2004 (01), 2005 (02), 2006 (05), 2007 (04), 2008 (00), 2009 (02), 2010 (01), 2011 (01), 2012 (01), 2013 (00), 2014 (03), 2015 (00) e 2016 (05). O gráfico 01 sintetiza as defesas de teses e dissertações localizadas por ano e instituição.

Gráfico 01 - Defesas por universidade/ano

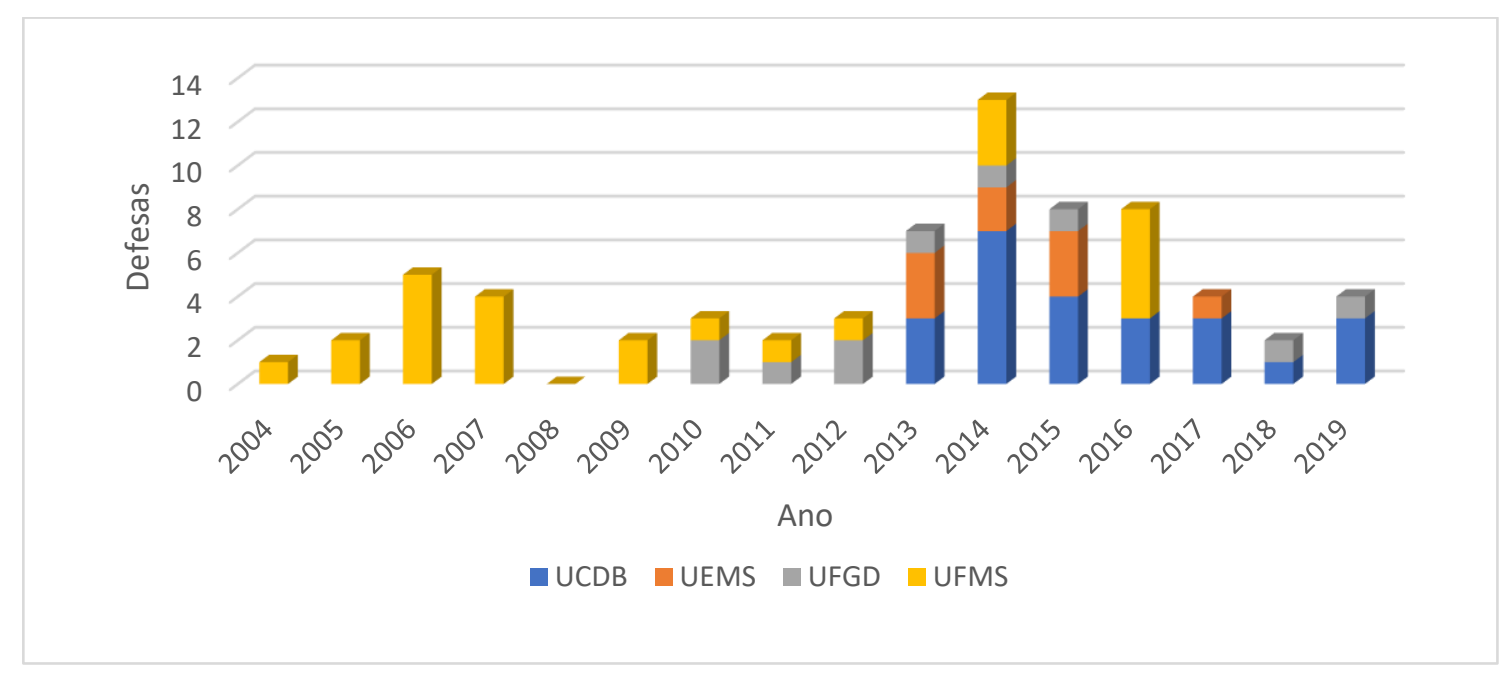

Fonte: elaborado pela autora, 2020.

A partir da soma dos trabalhos das quatro universidades, temos um total identificado de 40 docentes com orientações de trabalhos no período de 2004 a 2019 , totalizando 74 trabalhos entre dissertações e teses. Observa-se que em alguns programas poucos docentes concentram a orientação da maioria dos trabalhos sobre formação de professores, porém ao considerar os seis docentes com mais orientações nas quatro instituições, constatamos que esses tiveram 27 trabalhos defendidos, praticamente um terço do total de trabalhos (36,5\% do total), ou uma média de 4,5 trabalhos cada um. Outros 34 orientadores tiveram 47 trabalhos defendidos, com uma média de menos de dois trabalhos orientados cada um. Assim, pode-se perceber que existe um pequeno grupo responsável por grande parte da produção identificada.

A análise do Gráfico 01 indica que a partir de 2013 houve um crescimento do número de trabalhos sobre a temática decorrente, sobretudo, da criação de novos programas de mestrado e doutorado no estado, com destaque para a UCDB que tem forte presença nas discussões sobre o tema, ainda que, à exemplo das demais instituições, a formação compareça sob o viés da focalização em temas específicos. 
A redução do número de trabalhos nos anos de 2018 e 2019, provavelmente é decorrente da não disponibilização dos mesmos nos repositórios e nos endereções eletrônicos das próprias universidades.

\section{Apontamentos finais}

Inicialmente é importante apontar alguns limites desse tipo de investigação, constatados também em trabalhos anteriores e que permanecem na pesquisa aqui empreendida com destaque para a desatualização e incompletude dos bancos de dados, notadamente aqueles vinculados aos programas de pós-graduação investigados e a qualidade dos resumos.

Considerando esse apontamento inicial, os dados coletados permitem algumas conclusões. A produção da pós-graduação na área de educação localizada no Estado de Mato Grosso do Sul tem um crescimento recente, decorrente do processo de expansão das universidades públicas observadas na primeira década deste século. Portanto, um primeiro dado que se destaca nas pesquisas sobre formação de professores nos programas de educação de Mato Grosso do Sul é a sua própria emergência com a concentração maior de trabalhos em um período recente.

Os trabalhos analisados foram identificados pelos seus títulos, resumos e palavraschave que traziam expressões como formação de professores, formação continuada, formação inicial, ou termos assemelhados. Porém, uma análise mais detida dos conteúdos pesquisados permite localizar uma ampla variedade temática que, na maioria dos casos, não tem na formação de professores seu objeto de análise. São muitos os trabalhos que tratam da formação do "professor para...", no sentido de analisar sua formação inicial ou continuada a partir de um objeto de investigação definido, tais como programas de alfabetização, uso de tecnologias, conteúdo específico de disciplinas, entre outros.

Temos, portanto, análises da formação do professor para atuar na alfabetização, no uso das tecnologias, no ensino de uma disciplina específica, na educação especial e com alunos com deficiências, ou ainda, uma caraterística presente no estado, que analisa esses elementos em relação às escolas indígenas em uma intersecção de temas, como a alfabetização na escola indígena ou o uso da tecnologia nestas, entre outras discussões.

Pode-se concluir que é baixo o número de trabalhos que se debruçam sobre a formação de professores tendo-a como seu objeto de análise específico. As investigações que se aproximam dessa discussão são aquelas que estudam a formação inicial. Embora analisem esta formação em um lócus específico, esses trabalhos dialogam com a produção da área de formação de professores perpassando os sentidos e objetivos da formação, os movimentos da área e suas tensões, ainda que este debate esteja subordinado à discussão 
PESQUISAS SOBRE FORMAÇÃO DE PROFESSORES NO MATO GROSSO DO SUL:

0 que sinaliza a produção dos programas de pós-graduação em educação?

de uma formação em um curso, que também é objeto de reflexão, seja a formação do professor alfabetizador, do professor indígena, do professor de matemática, ou outras licenciaturas.

Pretende-se, oportunamente, ampliar a análise da produção sobre formação de professores no Estado de Mato Grosso do Sul, olhando para os programas das áreas afins. Possivelmente, localizaremos uma produção considerável sobre formação de professores em outros programas.

\section{Referências}

ANGELUCCI, C. B.; KALMUS, J.; PAPARELLI, R.; PATTO, M. H. S. O estado da arte da pesquisa sobre o fracasso escolar (1991-2002): um estudo introdutório. Educação e Pesquisa, São Paulo, v.30, n.1, p. 51-72, jan./abr. 2004.

BRZEZINSKI, I.; GARRIDO, E. Análise dos trabalhos do GT Formação de Professores: o que revelam as pesquisas do período 1992-1998. Rev. Bras. Educ., Rio de Janeiro, n. 18, p. 82-100, Dec. 2001. Disponível em: http://www.scielo.br/scielo.php?script=sci arttext\&pid=S1413-24782001000300008\&lng=en\&nrm=iso. Acesso em 02Abr. 2020.

BUENO, J. G. S.; SOUZA, S. B. de. A constituição do campo da educação especial expressa na Revista Brasileira de Educação Especial - RBEE (1992-2017). Rev. Bras. Ed. Esp., Marília, v.24, Edição Especial, p.33-50, 2018.

COSTA, A. B.; ZOLTOWSKI, A. P. C. Como escrever um artigo de revisão sistemática. In: KOLLER, S. H.; COUTO, M. C.; HOHENDORFF, J. (eds.). Manual de Produção Científica. Porto Alegre: Penso, 2014.

DAVIES, P. Revisões sistemáticas e a Campbell Collaboration. In: THOMAS, G.; PRING, R. Educação baseada em evidências: a utilização dos achados científicos para a qualificação da prática pedagógica. Porto Alegre: Artmed, 2007.

DINIZ-PEREIRA, J. E. A construção do campo da pesquisa sobre formação de professores. Revista da FAEEBA - Educação e Contemporaneidade, Salvador, v. 22, n. 40, p. 145-154, jul./dez. 2013.

DUARTE, A. A produção acadêmica sobre trabalho docente na educação básica no Brasil: 1987-2007. Educar em Revista, Curitiba, Brasil, n. especial 1, p. 101-117, 2010.

FERREIRA, N. S. de A. As pesquisas denominadas "estado da arte". Educação \& Sociedade, ano XXIII, no 79, agosto/2002.

MAGAlHÃES, A. M. da S. Políticas e expansão da pós-graduação stricto sensu nas Universidades Federais em Mato Grosso do Sul (2003-2016): uma análise das condições materiais e simbólicas. Tese (Doutorado em Educação). Dourados: Universidade Federal da Grande Dourados, 2019. 
MAGAlHAES, S. M. O.; SOUZA, R. C. C. R. de. A questão do método e da metodologia: uma análise da produção acadêmica sobre professores(as) da região CentroOeste/Brasil. Educ. Real., Porto Alegre, v. 37, n. 2, p. 669-693, ago. 2012. Disponível em http://www.scielo.br/scielo.php?script=sci_arttext\&pid=S2175-62362012000200018 \&lng=pt\&nrm=iso. Acesso em 02 abr. 2020.

NERES, C. C.; CORREA, N. M. Análise dos artigos na área da deficiência visual publicados na Revista Brasileira de Educação Especial (1992-2017). Rev. Bras. Ed. Esp., Marília, v.24, Edição Especial, p.153-166, 2018.

ROMANOWSKI, J. P. Tendências da pesquisa em formação de professores. Atos de Pesquisa em Educação, v. 8, n. 2, p.479-499, mai./ago. 2013.

ROMANOWSKI, J. P.; ENS, R. T. As pesquisas denominadas do tipo "estado da arte" em educação. Diálogo Educ., Curitiba, v. 6, n.19, p.37-50, set./dez. 2006.

ROMANOWSKI, J. P. Apontamentos em pesquisas sobre formação de professores: contribuições para o debate. Revista Diálogo Educacional, vol. 12, núm. 37, set./dez., 2012, pp. 905-924.

SILVA, L. V. da; BEGO, A. M. Levantamento Bibliográfico sobre Educação Especial e Ensino de Ciências no Brasil. Rev. Bras. Ed. Esp., Marília, v.24, n.3, p.343-358, jul./set., 2018.

*Andréia Nunes Militão é professora adjunta da Universidade Estadual de Mato Grosso do Sul (UEMS) e docente das licenciaturas em Pedagogia e Letras e do Programa de PósGraduação em Educação. Doutora em Educação pela UNESP, é líder do Grupo de Estudos e Pesquisa "Políticas Educacionais e Formação de Professores" (GEPPEF-UEMS-UFGD) e coordenadora do GT 08 da ANPED/Centro-Oeste.

E-mail: andreiamilitao@uems.br

ORCID Id: https://orcid.org/0000-0002-1494-8375 